\title{
GÊNERO, SEXUALIDADE E VIOLÊNCIA NA AMÉRICA LATINA: EXPULSÕES, DEPENDÊNCIA E INSURGÊNCIAS SOB OS LIMITES DA NECROPOLITICA
}

\section{Bruna Andrade Irineu'}

A América Latina é marcada pelo colonialismo e pela dependência em seu processo formativo, não apenas nos processos que envolvem sua colonização, mas fundamentalmente nas raízes da constituição do Estado-nação. A autonomia política, administrativa, econômica e territorial são centrais para compreender o Estado moderno, especialmente sob sustentação de estruturas e instituições impulsionadas pela perspectiva federalista articulada pelo viés do liberalismo. Neste sentido, Jaime Preciado e Pablo Uc (2010), escrevendo em um momento em que os países sul-americanos estão com suas economias em evidência, refletem sobre o direito à autodeterminação e autonomia democrática no redesenho dos Estados nacionais. Os autores destacam ainda que o processo latino-americano é delineado pelo colonialismo interno, logo a busca por autodeterminação e autonomia dizimou populações indigenas. E, no caso brasileiro, acrescenta-se o regime escravagista que traficou e escravizou milhares de negros e negras do continente africano, fato este nunca reparado na história nacional, germinal do racismo estrutural que forma o país.

Nas últimas duas décadas, a América Latina, após anos de processos ditatoriais em diversos países, viu governos populares ascenderem ao poder. Preciado e Uc (2010) identificaram, no fortalecimento das relações Sul-Sul, uma unidade geopolítica sustentada pelo modelo de desenvolvimento, pela gramática democrática de participação, representação e governabilidade. Todavia esses projetos tiveram uma inserção internacional que reforçou a dependência latino-americana, com modelo econômico que coaduna com formas predatórias.

Saskia Sassen (2016) nos oferece uma categoria importante para pensar a dinâmica atual do capitalismo - a ideia de "expulsões" será essencial para entendermos que mercado de terras, especulação no mercado imobiliário e as commodities, por exemplo, serão centrais para o novo mercado global, que também conhecemos como financeirização do capital. Assim, em um

1 Professora do Departamento de Serviço Social e do Programa de Pós-Graduação em Política Social da Universidade Federal de Mato Grosso (UFMT). Doutora em Serviço Social pela Universidade Federal do Rio de Janeiro (UFRJ). Presidente da Associação Brasileira de Estudos da Homocultura (ABEH) durante o biênio 2019-2020, Brasil. E-mail: brunairineu@gmail.com. Orcid: 0000-0003-1158-5000 
mesmo terreno de ampliação da participação social nos países com governos populares na América Latina, instituiu-se o projeto neodesenvolvimentista que se alinha ao movimento econômico global que mencionamos. $\bigcirc$ que vemos, sobretudo, são processos migratórios, que Sassen (2016) chama de expulsões, incluindo ainda entre as populações expulsas de territórios aquelas que estão em privação de liberdade.

Se o movimento econômico se tornou mundializado, é necessário ressaltar que a lógica financeira não opera sem articular a dimensão sociocultural. Elas são intrinsecamente relacionadas, e o que vemos hoje ao falar, por exemplo, dos usos da "ideologia de gênero" pelo bolsonarismo, governo este essencialmente ultraliberal pelas suas contrarreformas e estratégias de desmoralização das instituições democráticas, explicita bem isso. $\bigcirc$ governo Bolsonaro é um laboratório para a ultradireita mundial, logo o contexto de recrudescimento do conservadorismo, tergiversado pela barbárie do ultraliberalismo, demonstra ter se intensificado ao aliar-se à ofensiva antigênero (PRADO; CORREA, 2019) na América Latina, na Europa, na Ásia, nos Estados Unidos, entre outras regiões.

As tensões e disputas entre os movimentos sociais e o Estado, bem como as recentes respostas do poder público às demandas por combate à LGBTfobia e ao feminicídio nos contextos latino-americanos foram avanços importantes nas últimas duas décadas em países como Argentina, Colômbia, Uruguai, Chile, México, Equador, Paraguai e o próprio Brasil. Em processos e tempos distintos, os direitos sexuais e o direito à não discriminação têm se configurado em conquistas jurídico-legais no contexto latino-americano, mas não sem contrarrespostas. Os crimes de ódio e os ataques morais contra ativistas feministas e LGBTI aumentaram na mesma medida em que a cruzada antigênero (PRADO; CORREA, 2019) tem se ampliado desde o Poder Legislativo desses países e de outros nas demais regiões do globo.

$O$ ataque a Judith Butler e Wendy Brown no período do evento "Os fins da democracia" tem sido elencado como ponto fulcral na linha histórica do movimento que elegeu Bolsonaro à Presidência da República. Entretanto outros ataques a pesquisadoras e pesquisadores de gênero já vinham sendo feitos por mandatos como os da família Bolsonaro, Marcos Feliciano e de outros mais restritos às movimentações fora dos grandes centros. Esse movimento se capilarizou por meio do projeto Escola sem Partido, que foi fundamental para a retirada do termo "gênero" dos planos de educação e que já se articulava em torno da ofensiva antigênero no período do veto ao Kit Escola sem Homofobia, 
precursor das fake news "mamadeira de piroca", ocorridas ainda no primeiro mandato de Dilma Rousseff. As narrativas falaciosas sobre sexualidade, a defesa da familia tradicional, a relação com projetos econômicos neoliberais e com instituições criminosas se fundiram ao discurso antipetista de combate à corrupção, originando essa experiência que vivemos hoje.

Assim como a regressão de direitos por meio de contrarreformas, o ataque à educação e às universidades, o desmonte da cultura e a destruição do Sistema Único de Saúde são armas da atual necropolítica (Mbembe, 2018) brasileira, visiveis no modus operandi - de política de morte - usado pelo governo no contexto de pandemia da Covid-192. Todos esses elementos são trilhados à base de fake news, estratégia central no processo de desdemocratização (BROWN, 2015) que têm operado os governos da extrema-direita mundial.

Não obstante, procuramos, neste número da Revista Gênero, evidenciar a problemática da ascensão da ultradireita na América Latina, mas destacar especialmente as resistências e as insurgências de gênero, raça, etnia e sexualidade aos processos de violência e discriminação.

dossiê recebeu a submissão de 43 artigos, número que reforça a necessidade de construir espaços para diálogo e difusão de um pensamento latino-americano sobre gênero e sexualidade. Dentre esse número de trabalhos submetidos, o comitê de pareceristas ad hoc aprovou dez artigos, conforme a necessidade de composição deste dossiê. Dentre esses textos, buscou-se evidenciar processos distintos na(s) América(s) Latina(s) e temas variados que convergissem com a pluralidade de debates hoje em tela quanto à violência, gênero e sexualidade na região, como veremos a seguir.

Em "Resistencias feministas en Chile: subjetivaciones y acciones estético-políticas ante las violencias neoliberales", de Maria Laura Gutiérrez e Camila Arbuet Osuna, os desencontros entre movimentos feministas e LGBTQI+ no Chile são explicitados a partir da compreensão das violências estatais do neoliberalismo. $\bigcirc$ avanço do conservadorismo no Chile aparece como espectro da herança dos processos de subjetivação produtivista, sexista, racista e heteronormativa pinochetista.

No artigo "Trabalho, questão social e opressões: contribuições ao debate sobre violência de classe, raça e gênero no Brasil", de Josiley Carrijo Rafael, o trato da categoria questão social e suas refrações na forma de opressões

\footnotetext{
2 Embora todos os textos deste dossiê tenham sido submetidos até início do ano de 2020, nenhum deles foi redigido diante da conjuntura sanitária que vivemos nesta pandemia. Todavia muitos destes textos do dossiê já nos colocavam em alerta mediante a política de morte do atual governo.
} 
enfatiza a violência de classe, raça e gênero na particularidade brasileira. A partir da categoria trabalho e no acúmulo teórico da ontologia do ser social, o autor analisa a dinâmica da sociabilidade burguesa, analisando classe, racismo e heteropatriarcado como elementos estruturantes do capitalismo.

Camila Camargo Ferreira apresenta, em "A capilarização do combate à ideologia de gênero: produção de subjetividades e matabilidade", a capilaridade da politização da categoria "ideologia de gênero" no cenário político brasileiro e seus efeitos sobre as minorias sexuais e de gênero. Utilizando-se das reflexões de Michel Foucault e Giorgio Agamben acerca dos entrelaçamentos entre poder, vida e morte na modernidade, a autora afirma que o uso da noção de "ideologia de gênero" no espaço público tem sido uma estratégia de saber e poder voltada para a regulação dos corpos, do sexo, da sexualidade e do gênero. Ela demonstra ainda que a recente sinalização da inclusão do combate à "ideologia de gênero" na agenda política nacional intensifica a desvalorização das vidas dos sujeitos que escapam à heteronorma.

Fátima Lima e Julia B. Gambetta escrevem o texto intitulado "Parem de nos matar"': a bionecropolítica genderizada e a persistência de mulheres indígenas e negras na Améfrica Ladina". Elas tomam três dispositivos analíticos que envolvem fatos no Brasil, na Argentina e em Honduras para pensar a constituição de uma bionecropolítica genderizada que tem nas relações ético-raciais um elemento central que produz e legitima o extermínio de mulheres; o que consideram fundamental para entender como diagramas de poder são forjados e operam uma bionecropolítica genderizada no contexto da América Latina.

artigo "Análise sócio-histórica de constituição da cidade de Bogotál Colômbia e o lugar das mulheres em situação de rua", de Anyi Paola Munoz Umana e Leana Oliveira Freitas, revisa o processo histórico de constituição de Bogotá (Colômbia), destacando a negação, a invisibilidade e a interdição, nessa cidade, da população em situação de rua, com atenção particular às mulheres. A formação social, econômica, política e cultural de Bogotá, bem como seus efeitos na produção das relações sociais de raça, classe e gênero demarcam a atual realidade da construção do espaço urbanizado na América Latina.

Camila Rodrigues Francisco e Cláudia Mayorga apresentam, em "Insurgências nas trajetórias em diáspora de universitárias haitianas em Belo Horizonte, Brasil", um estudo que evoca desde a etimologia da palavra insurgência - organização que vai contra um movimento hegemônico, utilizada, sobretudo, para indicar rebelião contra um sistema social e político. 
Considerando isso, o artigo traz a diáspora haitiana motivada por questões estudantis, a partir da perspectiva de mulheres. $\bigcirc$ texto tem completa relação com o que abordamos no início da apresentação deste dossiê em relação às contribuições de Sassen (2016).

$\bigcirc$ artigo "Sertão, sertanejas e violência contra a mulher: análise dos dados estatísticos do Sertão de Pernambuco", de autoria de Kalline Flávia Silva de Lira, analisa os dados da violência doméstica e familiar contra a mulher na região do sertão do Araripe de Pernambuco, a partir de dados oficiais dos anos de 2015 a 2018. A autora investiu na correlação entre os marcadores de gênero e regionalidade como argumento possível para o reduzido número de solicitações de medidas protetivas de urgência, considerando as ocorrências registradas referentes à violência doméstica e familiar contra a mulher na região.

Maria de Fátima Pereira Carvalho e Carmem Lúcia Eiterer expõem, no texto "Violência de gênero: o que dizem as jovens mulheres na Educação de Jovens e Adultos do Alto Sertão da Bahia", um estudo realizado com jovens mulheres inseridas na Educação de Jovens e Adultos (EJA), no Alto Sertão da Bahia. $\bigcirc$ estudo aponta que as estudantes da EJA são mulheres, jovens, pobres, em sua maioria, negras e nordestinas que vivenciam enfrentamentos para permanecer no processo de escolarização, sendo a violência de gênero e o sexismo alguns deles.

"Crimes contra LGBTs no Brasil e o discurso do Estado pelos órgãos de segurança pública e jurídicos", de Valdenízia Bento Peixoto, analisa quatro assassinatos que envolvem motivação LGBTfóbica, com base na intepretação das instituições de segurança pública e jurídica do Estado brasileiro. A autora argumenta que as instituições jurídicas brasileiras conseguem resguardar o corpo LGBT, punir quem os golpeia, mas não conseguem dirimir a abjeção que interpela esses copos dissidentes, o que assinala o fato de que a inteligibilidade de gênero se perpetua no tecido social mesmo com mecanismos legais de punição de violência letal contra pessoas LGBT.

Paula Martins Sirelli, Gabrielle Gomes Ferreira e Ana Carolina Rodrigues Dias apresentam o texto "Consultório LGBT: (re)construindo narrativas de combate às violências LGBTfóbicas na saúde em Macaé/RJ". O artigo é fruto de uma pesquisa com o "Consultório LGBT", projeto dentro do Consultório na Rua, serviço público de saúde da cidade de Macaé (RJ). A comunicação dessa experiência é fundamental para a construção de narrativas de combate às violências LGBTfóbicas, com enfoque para a transfobia, nos contextos 
latino-americanos. Os resultados do estudo realizado com profissionais e usuários ilustra a dificuldade de incorporação dos ganhos materializados na Política Nacional de Saúde Integral LGBT, especialmente pela desinformação, pelo conservadorismo e o preconceito dos profissionais somados aos poucos investimentos da gestão municipal.

Cabe observar que, embora esse dossiê temático abarque um razoável espectro das violências de gênero e sexualidade na América Latina, muitas dimensões desse tema ficaram de fora. Acreditamos que há lacunas como o debate sobre migração, especialmente aquelas relacionadas a países que vivem hoje também a intensificação do conservadorismo, como a Bolívia por exemplo. Estudos comparativos entre as legislações sobre feminicídio e os indicadores de violência após sua regulamentação na Argentina, no México e no Brasil mereciam maior atenção, do mesmo modo que análises sobre acesso ao processo transexualizador e as políticas de trabalho e renda nos países que aprovaram a Lei de Identidade de Gênero. Outra lacuna é a ausência de artigos que pudessem, de maneira mais sólida, contemplar os fluxos sobre ativismos feministas e LGBT no enfrentamento à violência, a partir das estratégias artivistas e cyberativistas que ora se apresentam. Assim, cabe sublinhar aqui que, mesmo com lacunas, existe hoje no país uma produção sobre violência articulando gênero e sexualidade a outros marcadores sociais da diferença que complementa o esforço ora realizado neste dossiê.

Como afirmei no início deste texto, o esforço do editorial envolveu avaliação às cegas de consultores e consultoras ad hoc, a quem agradecemos com muita satisfação. Outro agradecimento necessário se faz à Kamila Teixeira, com quem dialoguei durante todo período que envolveu a proposta de chamada do dossiê, o processo de avaliação e seleção dos artigos. Agradeço às autoras e aos autores que aceitaram o chamado público a apresentar suas contribuições ao dossiê. E, sobretudo, queremos agradecer ao João Bôsco pelo espaço. Nossa expectativa é de que a leitura deste material possa inspirar lutas contra o sexismo, o racismo e a LGBTfobia, bem como fortalecer as demandas pelo debate de gênero e sexualidade nos espaços educacionais, discussão que envolve valores fundamentais para a defesa da democracia no Brasil. Em um contexto tão devastador, como este em que vivemos na pandemia de Covid-19, cabe a nós nos enlutarmos e lutarmos coletivamente em defesa das vidas que não são consideradas importantes, que são facilmente desumanizadas e que são passíveis de extermínio. 


\section{Referências}

BROWN, W. Undoing the demos: neoliberalism's stealth revolution. New York: Zone Books, 2015.

IRINEU, B. A. Nas tramas da política pública LGBT: um estudo crítico da experiência brasileira (2003-2015). Cuiabá: EdUFMT, 2019.

MBEMBE, A. Necropolítica. São Paulo: N-1 Edições, 2018.

PRADO, M. A. M.; CORRÊA, S. Retratos transnacionais e nacionais das cruzadas antigênero. Revista Psicologia Política, São Paulo, v. 18, n. 43, p. 444-448, 2018.

PRECIADO, J.; UC, P. La(s) autonomia(s) em América Latina: uma expresión sócio-espacial del Estado novíssimo y sus efectos em el proceso de integración. Orda L'ordinaire des Amériques, Toulouse, n. 2014, p. 199-220, 2010. Disponivel em: https://bit.ly/3ipW6xS. Acesso em: 10 jun. 2020.

SASSEN, S. Expulsões: brutalidade e complexidade na economia global. Rio de Janeiro: Paz \& Terra, 2016. 